\title{
Ziprasidone - Not Haloperidol - Induces more de-novo Neurogenesis of Adult Neural Stem Cells Derived from Murine Hippocampus
}

Authors

Affiliations
J. Benninghoff ${ }^{1,4}$, H. Grunze ${ }^{2}$, C. Schindler ${ }^{1}$, J. Genius ${ }^{1}$, R. J. Schloesser ${ }^{3}$, A. van der Ven ${ }^{1}$, S. Dehning ${ }^{1}$, J. Wiltfang ${ }^{4}$, H.-J. Möller ${ }^{1}$, D. Rujescu ${ }^{1}$

Affiliation addresses are listed at the end of the article

\author{
Key words \\ - ziprasidone \\ - haloperidol \\ - beta-III-tubulin-positive \\ neurons \\ - adult neural stem cells \\ - murine hippocampus \\ - de-novo generation
}

\begin{abstract}
$\nabla$

Introduction: Here, we present a stem-cell based study on the de-novo generation of beta-IIItubulin-positive neurons after treatment with the classic antipsychotic drug haloperidol or after treatment with the second-generation antipsychotic (SGA) ziprasidone.

Methods: Adult neural stem cells (ANSC) dissociated from the adult mouse hippocampus were expanded in cell culture with basic fibroblast growth factor (bFGF) and epidermal growth factor (EGF). ANSC differentiated upon withdrawal of EGF and bFGF.
\end{abstract}

\section{Introduction}

$\nabla$

Adult neurogenesis comprises a complex physiological cascade of events finally leading to the de novo generation of new neurons including the proliferation of resident neural stem cells, their differentiation, and functional integration into already existing neural circuitries [1]. As a consequence, disturbed adult neurogenesis has been linked to the etiopathology of psychiatric disorders. Specifically, decreased neural stem cell proliferation in the dentate gyrus of the hippocampus has been demonstrated in post-mortem human brain of schizophrenic patients [2].

These novel findings range among other meanderings, which have been observed in studies looking into pathological changes in schizophrenic patients. In this context, abnormalities in brain morphology have been reported frequently [3]. Although the data are still not unequivocal, the most prominent findings include total brain volume reductions and enlarged ventricles [4]. Also, there is evidence for alterations on the cellular level. They centre around the loss of regular cell morphology of large pyramidal neurons in the region of the dorsolateral prefrontal cortex
Results and Discussion: Ziprasidone generated significantly more beta-III-tubulin-positive neurons than haloperidol during the differentiation of adult neural stem cells isolated from murine hippocampus (ANSC). We assume that this net increase in neurogenesis by ziprasidone relies on this drug's $5-\mathrm{HT}_{1 \mathrm{~A}}$ receptor affinity, which is not present in the haloperidol molecule, since the inactivation by WAY100621 impeded this process. These data could possibly suggest a clinical relevance for studying antipsychotic drugs in the stem cell paradigm employed in this study.

[5] and a selective decrease in the number of parvalbumin-positive GABA-ergic interneurons in the hippocampus of the diseased [6]. Own experiments involving rat hippocampus have produced similar results after animal treatment by the NMDA-receptor antagonist MK-801 [7]. Although it seems far-fetched to interpret schizophrenia heretically as a neurodegenerative disease, the volume and cellular abnormalities might be indicative of a disturbed cellular repair mechanism by adult neural stem cells (ANSC). Moreover, Reif and co-workers reported a reduction in the number of stem cells in post-mortem hippocampi of schizophrenic patients [2].

Therefore, treatment options to restore full stem cell functioning could possibly become an option. Studies on antipsychotic drug-induced neurogenesis have already been conducted, but this survey on antipsychotic drugs looked particularly into the role of the serotonin $5 \mathrm{HT}_{1 \mathrm{~A}}$ receptor subtype in terms of the de-novo generation of new neurons, as a previous study by this group has shown that serotonin served as maintenance factor in hippocampus stem cells and this function was delivered by the $5-\mathrm{HT}_{1 \mathrm{~A}}$ receptor [8]: In a set of experiments, this particular receptor 
strongly influenced ANSC proliferation and stem cell survival. The group of Kempermann has demonstrated a differential impact of serotonin receptors on proper ANSC functioning emphasizing the $5-\mathrm{HT}_{1 \mathrm{~A}}$ receptor subtype's effect [9]. In addition, Santarelli [10] has revealed that this serotonin receptor is necessary for proper action of psychiatric medication improving anxiety. We have therefore chosen ziprasidone with its particular 5- $\mathrm{HT}_{1 \mathrm{~A}}$ receptor binding potential to be tested against the first generation antipsychotic haloperidol with no decisive $5-\mathrm{HT}_{1 \mathrm{~A}}$ receptor binding.

In order to investigate the mechanisms by which antipsychotic compounds may impact on neuroplastic features, we applied a standardized in-vitro neurosphere assay [11] of ANSC isolated and expanded from the dentate gyrus of mouse hippocampus.

The results demonstrate that ziprasidone significantly generated more new neurons compared to haloperidol. Furthermore, when the $5 \mathrm{HT}_{1 \mathrm{~A}}$ receptors were blocked by WAY100621, ziprasidone lost the neuroplastic superiority over haloperidol. The loss of cellular mobility after haloperidol or WAY100621 treatment may account for the disadvantage in terms of differentiation, since stem cell differentiation requires cellular mobility during the early steps of this process.

\section{Material and Methods}

$\nabla$

\section{Establishment of primary ANSC cultures}

Animals were treated according to $\mathrm{NIH}$ equivalent animal care rules. Study procedures were approved by the Regierung von Oberbayern, Munich (approval ID regarding the use of rodents for schizophrenia research 209.1/211.2531-78/03). Adult wildtype C57B6 mice (12 weeks old, Charles River Germany, Sulzfeld) were anesthetized by intraperitoneal injection of pentobarbital $(120 \mathrm{mg} / \mathrm{kg})$ and sacrificed by cervical dislocation. Brains were removed and placed in chilled PBS. Whole hippocampi were carefully removed and the dentate gyrus was identified. This structure was then digested in Eagle's balanced salt solution (EBSS) containing $0.94 \mathrm{mg} / \mathrm{mL}$ papain (purchased from Worthington Biochemicals), $0.2 \mathrm{mg} / \mathrm{mL}$ cysteine and EDTA (both Sigma) for $50 \mathrm{~min}$ at $37^{\circ} \mathrm{C}$ under gentle rocking. Digested dentates were washed twice in DMEM (Gibco Life), mechanically dissociated using a fire-polished Pasteur pipette, and finally placed in serum-free DMEM/F12 medium (1:1v/v; Gibco Life) containing $20 \mathrm{ng} / \mathrm{mL}$ EGF and $10 \mathrm{ng} / \mathrm{mL}$ FGF-2 (both human recombinant; Peprotech), $2 \mathrm{mM}$ L-glutamine, $0.6 \%$ glucose, $9.6 \mu \mathrm{g} / \mathrm{mL}$ putrescine, $6.3 \mu \mathrm{g} / \mathrm{mL}$ progesterone, $5.2 \mathrm{ng} / \mathrm{mL}$ sodium selenite, $0.025 \mathrm{mg} / \mathrm{mL}$ insulin, $0.1 \mathrm{mg} / \mathrm{mL}$ transferrin and $0.2 \mu \mathrm{g} /$ $\mathrm{mL}$ heparin (all Sigma) at a density of 20000 cells $/ \mathrm{cm}^{2}$ onto sterile, non-coated Petri dishes (Corning).

\section{Cell culturing and propagation}

Cells were serially subcultured by mechanical dissociation every 4-7 days. Cells were collected as neurospheres and the total number of viable cells was assessed each passage by trypan blue exclusion (Sigma). Self-renewal and multipotency were assessed every 3 subculturing passages $[11,12]$. For the experiments, 3 different ANSC cell lines at passages 5, 6, and 8 were used. ANSC were collected 5 days after the last subculturing passage. The total number of experimental samples for each experiment was $\mathrm{n}=20$ for differentiation and $\mathrm{n}=40$ for migration. All samples were analyzed in a blinded way.

\section{Cell culture treatments with different agents}

To ensure that the observed effects on proliferation and migration were not due to cytotoxicity, the toxic threshold levels of the administered drugs were assayed. For both haloperidol and ziprasidone $500 \mathrm{nM}$ was determined as an appropriate concentration, while $50 \mu \mathrm{M}$ was used for the $5-\mathrm{HT}_{1 \mathrm{~A}}$ receptor antagonist WAY100635. All concentrations were below $\mathrm{LD}_{50}$ by at least 2 orders of magnitude.

\section{Mobility assay}

For these experiments blind well or Boyden chambers were used [13]. Briefly, PVP-free polycarbonate filters with $8 \mu \mathrm{m}$ pores (Costar) were coated with Matrigel. DMEM (negative control), DMEM plus $500 \mathrm{nM}$ haloperidol or $500 \mathrm{nM}$ ziprasidone or regular growth medium as an internal standard containing EGF and FGF2 were placed in the lower chambers. Undifferentiated ANSCs with a regular cell diameter of $\sim 16 \mu \mathrm{m}$ were used for the assays $24 \mathrm{~h}$ following the last subculturing passage. 50000 cells were resuspended in $200 \mu \mathrm{L}$ DMEM and then placed in the upper chambers, where they were incubated for $6 \mathrm{~h}$. ANSCs remaining on the upper surface of the filters were mechanically removed, while those that had migrated to the lower surface were fixed with ethanol, Giemsa stained, and counted at 400 -fold magnification in 5 random fields per filter.

\section{Differentiation of stem cell progeny, and immunocytochemistry}

Undifferentiated ANSC were plated onto Matrigel-coated glass coverslips (Gibco Life) in growth medium. $6 \mathrm{~h}$ after plating, cultures were shifted to FGF2-containing medium, grown for 2 days, shifted to mitogen-free medium containing $2 \%$ FCS, grown for 5 days and then fixed (4\% paraformaldehyde in phosphatebuffered saline - PBS - pH 7.4, for $20 \mathrm{~min}$ ) and processed for immunofluorescence. In these cell cultures we evaluated the proportions of neurons. Primary antibody for the detection of neurons was monoclonal anti-TUJ1 (1:100, Covance) staining the neuron-specific class III beta-tubulin. Primary antibodies were incubated for $2 \mathrm{~h}$ at room temperature before adding Texasred conjugated donkey-anti-sheep (1:500) (Chemicon) for $30 \mathrm{~min}$ at room temperature. All cell nuclei were counterstained with DAPI (1:1000 dilution of stock solution, $10 \mathrm{~min}$ at room temperature) in order to assess the total number of differentiated cells. Samples were examined and photographed using a Nikon Eclipse 3000 fluorescence microscope at 640-fold magnification. Immunoreactive cells were counted in at least 5 nonoverlapping fields in each sample ( $>500$ cells/sample) and expressed as a percentage of the total number of nuclei. Fluorescent signals from single optical sections were sequentially acquired and analyzed by Photoshop 7.0 (Adobe).

\section{Statistical analysis}

Experimental data stem from differentiation and mobility experiments on adult neural stem cells. Within each group 20 differentiation experiments were performed independently $(n=20)$. Collected data passed one-way analysis of variance normality testing $(\mathrm{p}=0.666)$ and subsequent equal variance testing $(p=0.053)$. The differences in the mean values between groups were greater than would be expected by chance $(p<0.001)$. All experimental groups were then pairwise tested according to the Holm-Sidak method with an overall level of significance set at $p \leq 0.05)$. The data from the mobility shift experiments $(n=40)$ 
failed in the normality test. Therefore, ANOVA on ranks was performed revealing a statistically significant difference between the groups $(p<0.001)$. In order to isolate the group or the groups that differ from the others, we used Dunn's method as multiple comparison procedure with $\mathrm{p}<0.05$ as the indicator of significance.

\section{Results \\ $\boldsymbol{\nabla}$}

\section{Neurogenesis}

Based on previous work, we hypothesized the serotonin $5-\mathrm{HT}_{1 \mathrm{~A}}$ receptor subtype to play a pivotal role for differentiation of adult neural stem cells. As proven before, neurogenesis among other factors (EGF, FGF2, e.g.,) also depends on serotonin in general and on the $5 \mathrm{HT}_{1 \mathrm{~A}}$ receptor availability in particular. Since number and availability of neurons in the hippocampus seem to be crucial, we tested antipsychotic agents on their capacity to provide neurons.

At the end of the de-novo differentiation after 8 days, the newly generated neurons derived from undifferentiated murine hippocampus stem cells were identified by immunocytochemistry using the TUJ1 monoclonal antibody. In the untreated control group $10.8 \%$ (mean value, $\mathrm{SEM} \pm 0.1 \%$ ) of the de-novo differentiated cells in culture were neurons (i.e., beta-III-tubulin-positive), which is in due accordance with the general literature in this field ( $\bullet$ Fig. 1b, g).

After $500 \mathrm{nM}$ haloperidol treatment $7.5 \%(\mathrm{SEM} \pm 0.1 \%)$ of the cells became beta-III-tubulin-positive neurons ( $\bullet$ Fig. 1c). The difference of this group compared to control was statistically not significant $(\mathrm{p}>0.05)$. The second antipsychotic used was ziprasidone. Here, $16.2 \%$ (SEM $\pm 0.1 \%$ ) neurons surfaced after differentiation ( $\bullet$ Fig. 1d), which was statistically significant in comparison to both controls ( $\mathrm{p}<0.05$, $\bullet$ Fig. 1g§) and haloperidol treatment ( $\mathrm{p}<0.05$; $\odot$ Fig. 1g\#).

Based on previous studies, we hypothesized that these significant effects were due to the $5 \mathrm{HT}_{1 \mathrm{~A}}$ receptor activity of ziprasidone. Therefore, we impeded this receptor by adding $50 \mu \mathrm{M}$ of WAY100621 to $500 \mathrm{nM}$ ziprasidone. As a result of this, the proportion of neurons ( $\bullet$ Fig. 1e) decreased to $5.2 \%(S E M \pm 0.1 \%)$ and there was no statistical difference between this group and the haloperidol group. By contrast, when the ziprasidone/WAY group was tested against ziprasidone there was a significant difference between the 2 groups ( $\mathrm{p}<0.05$, $\odot$ Fig. 1 $\mathbf{g}^{*}$ ).

Finally, WAY100621 alone was assayed. In this scheme, the number of de-novo generated neurons ( $\bullet$ Fig. 1f) was $7.4 \%$ $(\mathrm{SEM} \pm 0.1 \%)$ revealing a significant effect compared to ziprasidone ( $p<0.05$, $\odot$ Fig. 1g\&), while no statistical effect was observed between this group and control or haloperidol ( $p>0.05$ each).

\section{Cell mobilization}

It has become increasingly evident that stem cell mobilization represents a stem cell characteristic, which is as important as proliferation or differentiation. Stem cell mobility brings appropriate numbers of stem cells to their correct locations in the brain, which is essential for establishing, maintaining and modifying the neural circuitry [14].

Haloperidol decreased the number of mobile cells in a statistically significant manner. After $6 \mathrm{~h}$ of incubation in the blindwell or Boyden chambers only 1 cell (median value) migrated (॰ Fig. 2), whereas in the untreated control group 2.5 cells
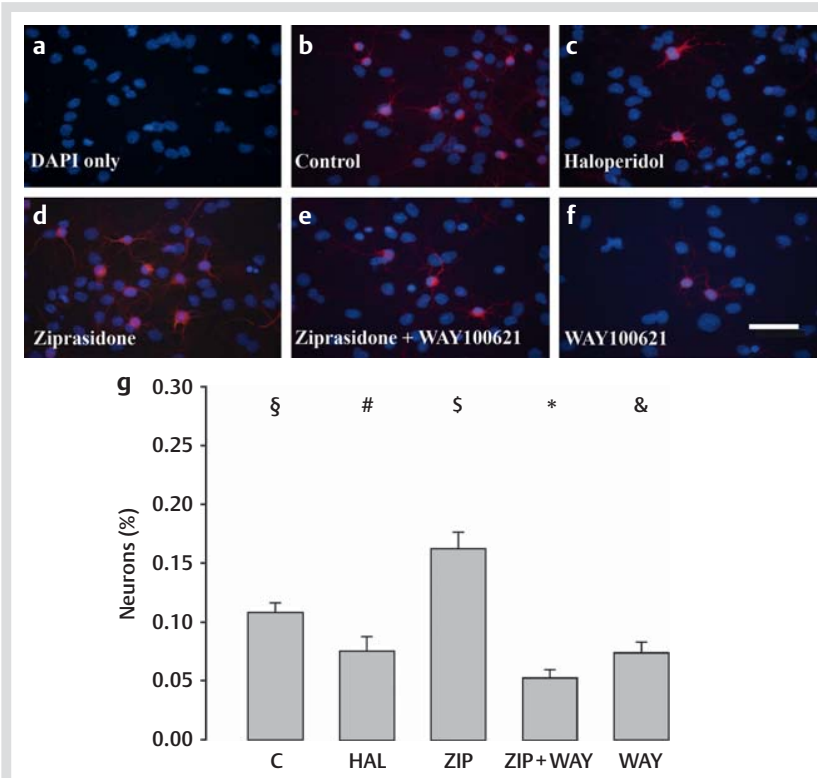

Fig. 1 Outcome after differentiation. Microscopic images (a-f) showing 400 -fold magnification of all cell nuclei stained by DAPI (blue) and by the neuronal marker beta-III-tubulin (red), white scale bar $\mathbf{f}$ measures $35 \mu \mathrm{m}$. Bar columns $\mathbf{g}$ representing the mean amount of neurons among all DAPI stained nuclei, column ticks showing the SEM; $p \leq 0.05$ for $\S$, \#, \$, *, and \&.

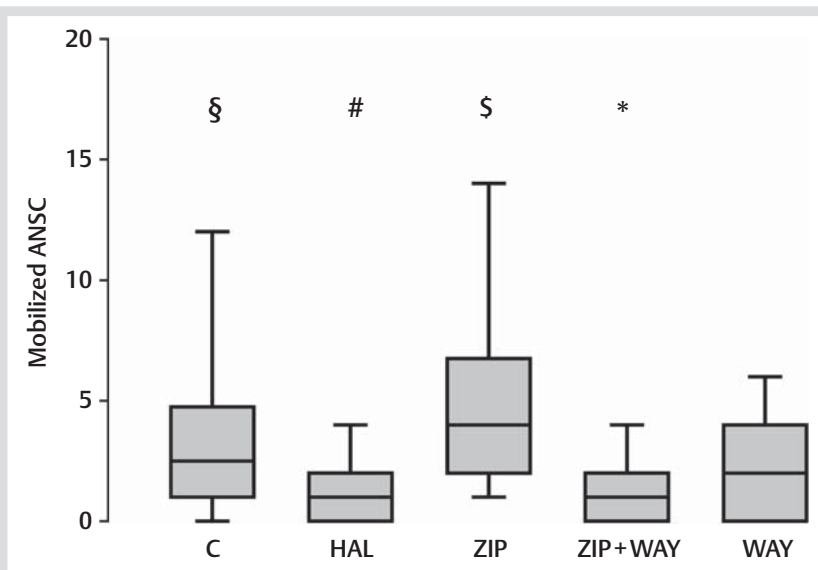

Fig. 2 Mobility assays. Box-and-whisker plots of the mobility assays representing the median value, with $50 \%$ of all data falling within the box. The "whiskers" extend to the $5^{\text {th }}$ and $95^{\text {th }}$ percentiles. Mobilized undifferentiated ANSC after no (C), haloperidol (HAL), ziprasidone (ZIP), ziprasidone + WAY100621 (ZIP+WAY), and WAY100621 (WAY) treatment; $\mathrm{p} \leq 0.05$ for $\S$, $\#, \$$, and *

(median value) did so. This was significant $(\mathrm{p}<0.05$, $\bullet$ Fig. $2 \S$ ) as well as the comparison of haloperidol and ziprasidone ( $p<0.05$, $\bigcirc$ Fig. $2 \#$ ). In the latter group 4 cells (median value) were chemotactically attracted by ziprasidone. This effect vanished after $5 \mathrm{HT}_{1 \mathrm{~A}}$ blockade by WAY100621 added to ziprasidone ( $p<0.05$, $\odot$ Fig. $2 \$$ ) resulting in one migrating cell during the given incubation period. Compared to control (2.5 cells) there was a negative chemotactic effect associated with $5 \mathrm{HT}_{1 \mathrm{~A}}$ blockade, which was significant $\left(\mathrm{p}<0.05\right.$, $\odot$ Fig. $\left.2^{*}\right)$.

No significance was detected between control and ziprasidone or WAY100621, or between haloperidol and WAY100621 or ziprasidone/WAY100621. 


\section{Discussion}

$\nabla$

In this survey, we examined the impact of haloperidol and ziprasidone on the de-novo differentiation of adult neural stem cells derived from mouse hippocampus. The outcome after the differentiation of ANSC into neurons has demonstrated that the second generation antipsychotic (SGA) ziprasidone generated significantly more new neurons than the classic first-generation antipsychotic (FGA) haloperidol. As underlying mechanism for these neuroplastic effects we suggest the particular affinity of ziprasidone to the serotonin receptor subtype 5- $\mathrm{HT}_{1 \mathrm{~A}}[15]$. After $5-\mathrm{HT}_{1 \mathrm{~A}}$ was blocked pharmacologically by WAY100621 the proneurogenic and chemotactic advantage of ziprasidone over haloperidol disappeared as this study indicates. In this vein, we suggest that the mobility of the stem cells represents a necessary condition for proper differentiation.

This study comparing the classic antipsychotic drug haloperidol with the second-generation antipsychotic ziprasidone looked particularly into the role of the $5-\mathrm{HT}_{1 \mathrm{~A}}$ receptor. This receptor was also subject of a study with the genetic $5-\mathrm{HT}_{1 \mathrm{~A}}$ receptor knock-out mouse model demonstrating the necessity of this receptor for the impact on behaviour and neurogenesis of the drug fluoxetine [10]. Here, this survey was conducted in a kind of "pharmacological knock-out model of the $5-\mathrm{HT}_{1 \mathrm{~A}}$ receptor". Further elucidating the possible mechanism how $5-\mathrm{HT}_{1 \mathrm{~A}}$ receptors influence adult neurogenesis, in-vivo data suggest that they can modulate cell proliferation in the hippocampus by a direct post-synaptic effect [16]. Apart from Santarelli's work it is further known that antidepressant drugs drive neurogenesis in the hippocampus acting on the serotonergic system through $5-\mathrm{HT}_{1 \mathrm{~A}}$ receptors $[17,18]$, while $5-\mathrm{HT}_{1 \mathrm{~A}}$ antagonists decrease cell proliferation in the dentate gyrus [19]. Although there are conflicting results on how serotonin impacts on neuroplastic effects like stem cell proliferation, survival and differentiation, Klempin et al. have suggested that the differential display of the several serotonin receptor subtypes explains some of the results, which might seem contradictory at first view [9]. Also, in-vitro data showed the enhancement of epidermal growth factor (EGF) signalling and an increased cell-turnover rate in fibroblasts transfected with the $5-\mathrm{HT}_{1 \mathrm{~A}}$ receptor $[20,21]$. Additional $5-\mathrm{HT}_{1 \mathrm{~A}}$ receptor stimulation was not undertaken in our experiments, since previous results have already elucidated the impact of the serotonergic system on ANSC and the positive correlation between the serotonergic system, its receptors and the neurogenic process have been investigated in detail [8,22-24].

Among the 2 other monoamines, dopamine has also been tested in relation to neurogenesis [25-27]. This connection is important, since the dopamine $\mathrm{D}_{2}$ receptor represents the classic target of first generation antipsychotics such as haloperidol, whereas the SGA ziprasidone has a comparably high affinity for serotonin receptors. Data from animal studies assessed ziprasidone's 5- $\mathrm{HT}_{2 \mathrm{~A}}$ receptor antagonizing affinity $\left(\mathrm{pK}_{\mathrm{i}} 9.38\right)$. This was about 10 times higher than the affinity to the $\mathrm{D}_{2}$ receptor $\left(\mathrm{pK}_{\mathrm{i}}\right.$ 8.32). For the purpose of this study, it is noteworthy to remember that ziprasidone is an agonist on the $5-\mathrm{HT}_{1 \mathrm{~A}}$ receptor $\left(\mathrm{pK}_{\mathrm{i}}\right.$ 8.47 ), and it antagonizes the $5-\mathrm{HT}_{2 \mathrm{~A}}$ and the dopamine $\mathrm{D}_{2}$ receptor. Contrary to this, haloperidol does not bind to the $5-\mathrm{HT}_{1 \mathrm{~A}}$ receptor [28].

Still, in order to exclude synergistic toxic effects of the WAY100621 compound and haloperidol apart from receptor antagonism, we included a combined WAY/haloperidol group in our experimental set-up although knowing there is no haloperidol 5- $\mathrm{HT}_{1 \mathrm{~A}}$ receptor interaction.

Although stem cell proliferation was not subject of this report, it should be mentioned that previous work suggested an influence of the $D_{2}$ receptor inactivation by haloperidol, which led to an increase in ANSC proliferation in rodent animal models [29,30]. This finding is contrasting with results showing that chronic clozapine, but not haloperidol, treatment increased the number of proliferating cells in the hippocampus. Both of these drugs had no effect on cell survival [31].

The major part of studies that investigated neurogenesis and antipsychotics used haloperidol either as a reference or as the primary drug of interest. Concerning atypical or second-generation antipsychotic drugs most of the reports analyzed olanzapine [32] and risperidone $[33,34]$. As a common denominator, nearly all studies took haloperidol as the comparator check with the SGA. By contrast, studies on ziprasidone examining this antipsychotic compound and neurogenesis with particular interest for the role of the $5-\mathrm{HT}_{1 \mathrm{~A}}$ receptor are very rare or not present.

Adult neural stem cells derived from murine hippocampus cultured in serum-free medium with EGF and FGF differentiated into more new neurons in a statistically significant manner after ziprasidone was added to the media compared to both control and ANSC treated with haloperidol as this survey has proven. By contrast to the results reported here, haloperidol caused an increase of de-novo generated neurons in a different set-up, which used the salamander, a non-mammalian model [35]. The species difference may explain the divergent results to some extent, since it has been shown that even within the same species, different mouse strains (Balb/cJ and 129SvEvTac) could produce different results [36].

Most of the models commonly employed mimic the so-called negative symptomatology (apathy, anhedonia, lack of emotion) and adjunctive cognitive defects, which are produced by psychostimulants [e.g., MK-801 or phencyclidine (PCP)] inferring with the regular balance of the glutamatergic and the GABAergic system. In such a model clozapine, but not haloperidol, prevented the decrease in neurogenesis after mice were treated by PCP [37].

We want to emphasize that the target of our cell culture model is not mimicking schizophrenia. Instead, we want to decipher pharmacological mechanisms of drug action. Therefore, we used a genetically unaltered, non-viral and non-oncogenic cell culture taking into account that most of the in-vitro cell culture experiments were done with cell lines derived from tumor tissue like PC12 cells [38]. The advantage of ANSC lies in the ability to generate permanent cell lines, which differentiate into neurons under given conditions without possible interference with - for the purpose of understanding pharmacological pathways - the surrounding tissue. In doing so, we achieve a reduction in the complexity for the gain of insight into molecular function of single cell types and the process of neurogenesis. Due to this experimental paradigm, it was not possible to address potentially cardiotoxic effects caused by ziprasidone, although a recent study has shown that ziprasidone's putative cardiotoxicity is within the regular range of SGA drugs [39].

Furthermore, we did not test the various hypotheses and their underlying mechanism leading to the onset of schizophrenia like other groups who showed, for example, that risperidone inhibited the production of interferon gamma induced microglial activation, which in turn possibly could contribute to schizo- 
phrenia $[34,40]$. Ziprasidone produced similar results in analogous experiments, respectively [41]. Haloperidol did not have any effect on neurogenesis in the rat hippocampus in a kanaic acid hippocampus deletion model [32]. In terms of mobility, another SGA drug, olanzapine, revealed a positive chemotactic effect [42].

Although the total of the migrated cells appears small, the statistically significant results from the mobility experiments reflect the main message of this study - that ziprasidone's neuroplastic properties are due to its $5-\mathrm{HT}_{1 \mathrm{~A}}$ receptor activation. Impeding this receptor by WAY100621 produces similar results resembling those of the haloperidol and the WAY/ziprasidone group. Additional studies going beyond the approach used here would be needed to rule out the notion that other factors than the direct inhibition of the $5-\mathrm{HT}_{1 \mathrm{~A}}$ receptor by WAY100621 have caused this outcome taking into account that the neurosphere assay used is considered controversial by some authors [43]. In general, the results presented here are in accordance with previous studies on the serotonergic system [8] and may be clinically involved in conferring potential SGA benefits of memory function and cognition. The newly generated neurons become part of existing neural networks and project to the CA3 layer where they form synapses and receive input from the perforant path [44]. Taken together, our data indicate a role for ziprasidone in augmenting de-novo neural differentiation and maintaining mobilization of ANSC-derived neuronal progenitors. It is tempting to speculate that this may partially account for improved cognition in patients treated with ziprasidone as compared to patients treated with haloperidol [45], which hampered ANSC migration and differentiation in our experiments. In general, the neurogenic region of the hippocampus is crucial for learning and memory, all cognitive functions compromised in schizophrenic patients. To put it cautiously, our observations might partially explain the often postulated positive effects of SGA on cognition. We are very well aware that this interpretation is highly speculative, but hope that this study becomes a pilot to stimulate future translational studies connecting the laboratory bench to the bedside.

\section{Acknowledgements \\ $\nabla$}

The authors wish to thank Beate Kauschat for the excellent technical assistance and Hans Klafki and Nico Rohlfing for proofreading and comments on the manuscript.

\section{Conflict of Interest \\ $\nabla$}

Yes: Funding of this study was provided by an Investigator initiated independent research grant from Pfizer Co, New York. Pfizer had no influence on study design, interpretation of data, or the writing of this report. JB, DR and HG designed the study, wrote the protocol and supervised the experiments. JG, CS, RS and SD assisted during the experiments and HJM served as additional supervisor to the study. All authors approved the final manuscript. HG and HJM have consulted for Pfizer, all other authors declare that they have no conflict of interest.

\section{Affiliations}

${ }^{1}$ Department of Psychiatry, LMU-University of Munich, Munich, Germany ${ }^{2}$ Institute of Neuroscience, Newcastle University, Newcastle, United Kingdom

${ }^{3}$ Laboratory of Molecular Pathophysiology, Mood and Anxiety Disorders

Programm, National Institute of Mental Health, NIH, Bethesda, USA

${ }^{4}$ Department of Psychiatry, University Hospital of Essen, Essen, Germany

\section{References}

1 Ehninger D, Kempermann G. Neurogenesis in the adult hippocampus. Cell Tissue Res 2008; 331: 243-250

2 Reif $A$, Fritzen $S$, Finger $M$ et al. Neural stem cell proliferation is decreased in schizophrenia, but not in depression. Mol Psychiatry 2006; 11: 514-522

3 Steen RG, Mull C, McClure $R$ et al. Brain volume in first-episode schizophrenia: systematic review and meta-analysis of magnetic resonance imaging studies. Br J Psychiatry 2006; 188: 510-518

4 Walker MA, Highley JR, Esiri MM et al. Estimated neuronal populations and volumes of the hippocampus and its subfields in schizophrenia. Am J Psychiatry 2002; 159: 821-828

5 Selemon $L D$, Rajkowska G. Cellular pathology in the dorsolateral prefrontal cortex distinguishes schizophrenia from bipolar disorder. Curr Mol Med 2003; 3: 427-436

6 Zhang ZJ, Reynolds GP. A selective decrease in the relative density of parvalbumin-immunoreactive neurons in the hippocampus in schizophrenia. Schizophr Res 2002; 55: 1-10

7 Braun I, Genius J, Grunze $H$ et al. Alterations of hippocampal and prefrontal GABAergic interneurons in an animal model of psychosis induced by NMDA receptor antagonism. Schizophr Res 2007; 97: 254-263

8 Benninghoff J, Gritti A, Rizzi $M$ et al. Serotonin depletion hampers survival and proliferation in neurospheres derived from adult neural stem cells. Neuropsychopharmacology 2010; 35: 893-903

9 Klempin F, Babu H, Tonelli Dde P et al. Oppositional effects of serotonin receptors 5 -ht $1 \mathrm{a}, 2$, and $2 \mathrm{c}$ in the regulation of adult hippocampal neurogenesis. Front Mol Neurosci 2010; 3

10 Santarelli L, Saxe M, Gross C et al. Requirement of hippocampal neurogenesis for the behavioral effects of antidepressants. Science 2003; 301: 805-809

11 Gritti A, Frolichsthal-Schoeller P, Galli $R$ et al. Epidermal and fibroblast growth factors behave as mitogenic regulators for a single multipotent stem cell-like population from the subventricular region of the adult mouse forebrain. J Neurosci 1999; 19: 3287-3297

12 Gritti A, Vescovi AL, Galli R. Adult neural stem cells: plasticity and developmental potential. J Physiol Paris 2002; 96: 81-90

13 Palumbo R, Sampaolesi M, De Marchis $F$ et al. Extracellular HMGB1, a signal of tissue damage, induces mesoangioblast migration and proliferation. J Cell Biol 2004; 164: 441-449

14 Ghashghaei HT, Lai C, Anton ES. Neuronal migration in the adult brain: are we there yet? Nature Rev 2007; 8: 141-151

15 Schmidt AW, Lebel LA, Howard HR Jr et al. Ziprasidone: a novel antipsychotic agent with a unique human receptor binding profile. Eur J Pharmacol 2001; 425: 197-201

16 Huang GJ, Herbert J. The role of 5-HT1A receptors in the proliferation and survival of progenitor cells in the dentate gyrus of the adult hippocampus and their regulation by corticoids. Neuroscience 2005; 135: $803-813$

17 Gould E. Serotonin and hippocampal neurogenesis. Neuropsychopharmacology 1999; 21: 46S-51S

18 Malberg JE, Eisch AJ, Nestler EJ et al. Chronic antidepressant treatment increases neurogenesis in adult rat hippocampus. J Neurosci 2000; 20: 9104-9110

19 Radley JJ, Jacobs BL. 5-HT1A receptor antagonist administration decreases cell proliferation in the dentate gyrus. Brain Res 2002; 955: 264-267

20 Varrault A, Bockaert J, Waeber C. Activation of 5-HT1A receptors expressed in NIH-3T3 cells induces focus formation and potentiates EGF effect on DNA synthesis. Mol Biol Cell 1992; 3: 961-969

21 Varrault A, Journot L, Audigier Y et al. Transfection of human 5-hydroxytryptamine $1 \mathrm{~A}$ receptors in $\mathrm{NIH}-3 \mathrm{~T} 3$ fibroblasts: effects of increasing receptor density on the coupling of 5-hydroxytryptamine1A receptors to adenylyl cyclase. Mol Pharmacol 1992; 41: 999-1007

22 Brezun JM, Daszuta A. Depletion in serotonin decreases neurogenesis in the dentate gyrus and the subventricular zone of adult rats. Neuroscience 1999; 89: 999-1002 
23 Brezun JM, Daszuta A. Serotonin may stimulate granule cell proliferation in the adult hippocampus, as observed in rats grafted with foetal raphe neurons. Eur J Neurosci 2000; 12: 391-396

24 Banasr $M$, Hery $M$, Printemps $R$ et al. Serotonin-induced increases in adult cell proliferation and neurogenesis are mediated through different and common 5-HT receptor subtypes in the dentate gyrus and the subventricular zone. Neuropsychopharmacology 2004; 29: 450-460

25 Borta A, Hoglinger GU. Dopamine and adult neurogenesis. J Neurochem 2007; 100: 587-595

26 Hoglinger GU, Rizk P, Muriel MP et al. Dopamine depletion impairs precursor cell proliferation in Parkinson disease. Nat Neurosci 2004; 7: 726-735

27 Van Kampen JM, Eckman CB. Dopamine D3 receptor agonist delivery to a model of Parkinson's disease restores the nigrostriatal pathway and improves locomotor behavior. J Neurosci 2006; 26: 7272-7280

28 Newman-Tancredi A, Assie MB, Leduc $N$ et al. Novel antipsychotics activate recombinant human and native rat serotonin 5-HT1A receptors: affinity, efficacy and potential implications for treatment of schizophrenia. The international journal of neuropsychopharmacology/ official scientific journal of the Collegium Internationale Neuropsychopharmacologicum (CINP) 2005; 8: 341-356

29 Kippin TE, Kapur S, van der Kooy D. Dopamine specifically inhibits forebrain neural stem cell proliferation, suggesting a novel effect of antipsychotic drugs. J Neurosci 2005; 25: 5815-5823

30 Dawirs RR, Hildebrandt K, Teuchert-Noodt G. Adult treatment with haloperidol increases dentate granule cell proliferation in the gerbil hippocampus. J Neural Transm 1998; 105: 317-327

31 Halim ND, Weickert CS, McClintock BW et al. Effects of chronic haloperidol and clozapine treatment on neurogenesis in the adult rat hippocampus. Neuropsychopharmacology 2004; 29: 1063-1069

32 Csernansky JG, Martin MV, Czeisler B et al. Neuroprotective effects of olanzapine in a rat model of neurodevelopmental injury. Pharmacol Biochem Behav 2006; 83: 208-213

33 Keilhoff G, Grecksch G, Bernstein HG et al. Risperidone and haloperidol promote survival of stem cells in the rat hippocampus. Eur Arch Psychiatry Clin Neurosci 2010; 260: 151-162

34 Kato T, Monji A, Hashioka $S$ et al. Risperidone significantly inhibits interferon-gamma-induced microglial activation in vitro. Schizophrenia Res 2007; 92: 108-115
35 Berg DA, Kirkham M, Wang H et al. Dopamine controls neurogenesis in the adult salamander midbrain in homeostasis and during regeneration of dopamine neurons. Cell Stem Cell 2011; 8: 426-433

36 Holick KA, Lee DC, Hen $R$ et al. Behavioral effects of chronic fluoxetine in BALB/cJ mice do not require adult hippocampal neurogenesis or the serotonin $1 \mathrm{~A}$ receptor. Neuropsychopharmacology 2008; 33 : 406-417

37 Maeda K, Sugino H, Hirose $T$ et al. Clozapine prevents a decrease in neurogenesis in mice repeatedly treated with phencyclidine. J Pharmacological Sci 2007; 103: 299-308

38 Greene LA, Tischler AS. Establishment of a noradrenergic clonal line of rat adrenal pheochromocytoma cells which respond to nerve growth factor. Proc Natl Acad Sci USA 1976; 73: 2424-2428

39 Strom BL, Eng SM, Faich $G$ et al. Comparative mortality associated with ziprasidone and olanzapine in real-world use among 18154 patients with schizophrenia: The Ziprasidone Observational Study of Cardiac Outcomes (ZODIAC). Am J Psychiatry 2011; 168: 193-201

40 Keilhoff G, Grecksch G, Becker A. Haloperidol normalized prenatal vitamin D depletion-induced reduction of hippocampal cell proliferation in adult rats. Neurosci Lett 2010; 476: 94-98

41 Bian $Q$ Kato T, Monji A et al. The effect of atypical antipsychotics, perospirone, ziprasidone and quetiapine on microglial activation induced by interferon-gamma. Progr Neuro-psychopharmacol Biol Psychiatry 2008; 32: 42-48

42 Wang HD, Dunnavant FD, Jarman $T$ et al. Effects of antipsychotic drugs on neurogenesis in the forebrain of the adult rat. Neuropsychopharmacology 2004; 29: 1230-1238

43 Suslov ON, Kukekov VG, Ignatova TN et al. Neural stem cell heterogeneity demonstrated by molecular phenotyping of clonal neurospheres. Proc Natl Acad Sci USA 2002; 99: 14506-14511

44 Markakis EA, Gage FH. Adult-generated neurons in the dentate gyrus send axonal projections to field CA3 and are surrounded by synaptic vesicles. J Comparative Neurol 1999; 406: 449-460

45 Malhotra AK, Burdick KE, Razi $K$ et al. Ziprasidone-induced cognitive enhancement in schizophrenia: specificity or pseudospecificity? Schizophrenia Res 2006; 87: 181-184 